\title{
Understanding the Effect of a Paint Bake Cycle on the Microstructure-Mechanical Properties Relationship of a Resistance Spot Welded Advanced High Strength Steel
}

\author{
P. EFTEKHARIMILANI, E.M. VAN DER AA, R. PETROV, M.J.M. HERMANS, \\ and I.M. RICHARDSON
}

\begin{abstract}
The effect of an automotive paint bake (PB) thermal cycle on the microstructural evolution and the mechanical properties of resistance spot welded advanced high strength steel is presented in this work. Mechanical behavior of the heat-treated welds reveals an increase in maximum cross-tension strength, displacement and subsequently energy absorption capability when $453 \mathrm{~K}$ $\left(180{ }^{\circ} \mathrm{C}\right)-20$ minutes a bake thermal cycle is applied after welding. The microstructures of resistance spot welds with and without a PB heat treatment were characterized using scanning and transmission electron microscopy (TEM). TEM analysis revealed that the weld nugget and HAZ of the resistance spot welds consist of a martensitic microstructure. The microstructural analysis of the post-weld heat-treated samples shows the presence of $\varepsilon$ carbides in a martensitic matrix within the weld nugget and the HAZ. It is shown that the improved mechanical response of the paint-baked welds is associated with carbide precipitation during heat treatment.
\end{abstract}

https://doi.org/10.1007/s11661-018-4912-9

(C) The Author(s) 2018

\section{INTRODUCTION}

THE use of advanced high strength steels (AHSSs) is increasingly preferred in the automotive industry as a result of an enhanced strength-ductility combination and superior crashworthiness compared with conventional high strength steels. These properties rely on advanced multiphase microstructures, based on selectively designed alloying concepts and thermal-mechanical process cycles. The higher alloying compositions required to achieve the desired mechanical properties can have a negative effect on the weldability of these steels.

The most widely used joining method in automotive applications is resistance spot welding (RSW) due to its high speed, robustness, and low-cost. ${ }^{[1-3]}$ The high

P. EFTEKHARIMILANI, M.J.M. HERMANS, and I.M. RICHARDSON are with the Department of Materials Science and Engineering, Delft University of Technology, Mekelweg 2, 2628 CD Delft, The Netherlands. Contact e-mail: p.eftekharimilani@tudelft.nl E.M. VAN DER AA is with Tata Steel, 1970 CA, IJmuiden, The Netherlands. R. PETROV is with the Department of Materials Science and Engineering, Delft University of Technology and also with the Department of Materials, Textiles and Chemical Engineering, Ghent University (UGent), Tech Lane Ghent Science Park-Campus A, Technologie park 903, 9052 Ghent, Belgium.

Manuscript submitted March 6, 2018.

Article published online September 21, 2018 heating and cooling rates during RSW destroy the original AHSSs microstructures. As a result of the weld thermal cycle combined with high alloying content, the final weld nugget and HAZ microstructure of most AHSSs are almost fully martensitic. Due to the brittleness of the martensitic microstructure, welds in AHSSs do not always show satisfactory mechanical performance. In general, it is observed that the mechanical strength of resistance spot welds subjected to peel type loads tends to decrease for AHSS with a base material tensile strength above $800 \mathrm{MPa}{ }^{[4]}$

Re-heating has proven to be an efficient method to modify the microstructure and subsequently the mechanical properties of the welds. ${ }^{[5-17]}$ This can be achieved by using twin spot laser welding, ${ }^{[11-16]}$ where the second beam affects the cooling stage of the thermal cycle. A twin spot laser welding ${ }^{[14]}$ was reported to decrease the hardness of the fusion zone. Also, applying a twin-spot laser welding on a TRIP steel ${ }^{[13]}$ showed a significantly affected microstructure and hardness profiles of the weld joints. Another approach of re-heating is applying a second current pulse (post pulsing) during the RSW process. ${ }^{[5-10]}$ It is reported in our previous works $^{[7,10]}$ that the second current pulse partially anneals the solidified weld nugget, which changes the elemental distribution (such as phosphorous) and improves the lath martensite substructure at the weld nugget edge, thereby significantly improving the cross tension strength (CTS) performance. Both twin spot 
laser welding and double pulse RSW techniques have positive effects on the mechanical performance of the welds.

During automotive manufacturing, after assembly, the body-in-white is subjected to a paint bake (PB) cycle. The typical PB cycle heats the material to $\sim 453 \mathrm{~K}$ $\left(180{ }^{\circ} \mathrm{C}\right)$ for 20 minutes in order to bake the paint on the structure as well as hardening and curing coatings and adhesives. It is known that a typical PB cycle increases the yield strength of steel similar to the yield strength increment in bake hardenable steel grades. ${ }^{[18,19]}$ The thermal cycle may also temper the martensite. ${ }^{[20]}$ Depending on the alloying content of the base material, the PB cycle could lead to different stages of martensite tempering. ${ }^{[20]}$

The effect of a PB thermal cycle on mechanical properties of resistance spot welded steels has been reported in the literature. ${ }^{21-23]}$ However, no detailed study relating the effect of the baking cycle on the microstructures to the mechanical performance under peel type loading has been reported. In this paper, the results of the microstructural characterization and mechanical performance of single and double pulse welded AHSS combined with PB thermal cycle will be presented in detail.

\section{EXPERIMENTAL APPROACH}

The material examined was a AHSS with a thickness of $1.3 \mathrm{~mm}$. The steel was received in a cold-rolled and galvanized condition (surface density of $50 \mathrm{~g} / \mathrm{m}^{2}$ ). Material characteristics and composition are according to the VDA chemistry for CR700Y980T-DH in the recently drafted VDA specifications, ${ }^{[24]}$ as listed in Table I. The material microstructure consists of $80 \mathrm{pct}$ bainite, 10 pct martensite, 7 pct ferrite, and 3 pct retained austenite.

RSW was carried out on a Schlattes ${ }^{\mathrm{TM}} 50 \mathrm{~Hz}$ AC spot welding machine using F1 $16 \times 5.5$ electrodes with a holding force of $4 \mathrm{kN}$ and welding parameters, as described in the VDEh SEP1220-2 standard. ${ }^{[25]}$ Two weld schedules were taken into account: a standard single pulse weld schedule, as well as a double pulse weld schedule, consisting of two equal current pulses, as described in Reference 7. The welding parameters used to prepare the spot weld samples are listed in Table II. The highest possible current of $6.6 \mathrm{kA}$ was chosen to produce the largest weld size without expulsion. The post heat treatment cycles for the single pulseheat-treated (single pulse-PB) and double pulseheat-treated (double pulse-PB) welds involve a typical PB heat treatment of the welded samples at $453 \mathrm{~K}$ $\left(180^{\circ} \mathrm{C}\right)$ for 20 minutes. Thermocouples were placed in the oven to monitor the temperature. The estimated heating rate was $5 \mathrm{~K} / \mathrm{s}$ and after $\mathrm{PB}$ thermal cycle, the sample was air-cooled.

Microstructural characterization was carried out on the nugget of the welds using scanning and transmission electron microscopy (TEM). For scanning electron microscopy (SEM), the samples were polished and etched with 5 pct Nital for 5 seconds. For the 
Table II. Welding Parameters

\begin{tabular}{lcccccccc}
\hline Weld & $\begin{array}{c}\text { No. of } \\
\text { Pulses }\end{array}$ & $\begin{array}{c}\text { Squeeze } \\
\text { Time }(\mathrm{ms})\end{array}$ & $\begin{array}{c}\text { Weld Current } \\
1(\mathrm{kA})\end{array}$ & $\begin{array}{c}\text { Weld Time 1 } \\
(\mathrm{ms})\end{array}$ & $\begin{array}{c}\text { Cool } \\
\text { Time }(\mathrm{ms})\end{array}$ & $\begin{array}{c}\text { Weld Current } \\
2(\mathrm{kA})\end{array}$ & $\begin{array}{c}\text { Weld Time 2 } \\
(\mathrm{ms})\end{array}$ & $\begin{array}{c}\text { Hold Time } \\
(\mathrm{ms})\end{array}$ \\
\hline Single Pulse & 1 & 400 & 6.6 & 320 & - & - & - & 200 \\
Single Pulse-PB & 1 & 400 & 6.6 & 320 & - & - & - & 200 \\
Double Pulse & 2 & 400 & 6.6 & 320 & 40 & 6.6 & 320 & 200 \\
Double Pulse-PB & 2 & 400 & 6.6 & 320 & 40 & 6.6 & 320 & 200 \\
\hline
\end{tabular}

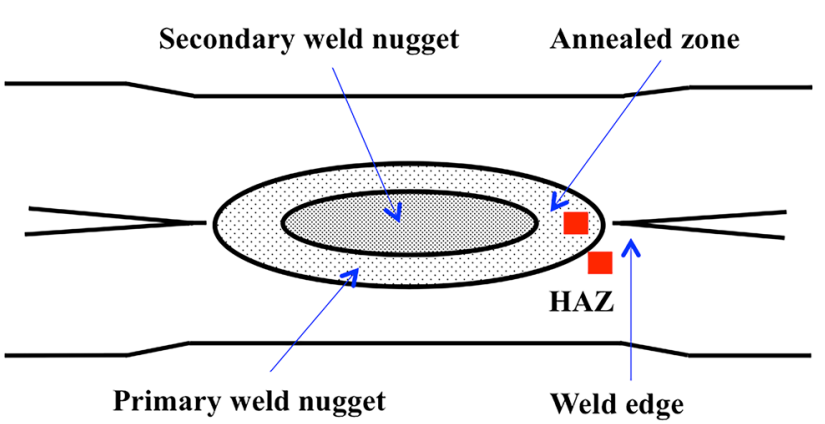

Fig. 1-Schematic representation of the locations where SEM and TEM samples were taken (colored squares). The dotted area is the primary weld nugget (Color figure online).

preparation of the TEM samples, conventional thin foils were extracted from the weld nugget and HAZ of the samples. The welds were cut to $0.2 \mathrm{~mm}$ thick sheets using a low-speed diamond-cutting wheel. The thickness of each sample was reduced mechanically to $0.1 \mathrm{~mm}$. Disks with a diameter of $3 \mathrm{~mm}$ were punched. To reduce thickness further, the disks were electro-polished using an electrolyte of 15 pct hydrochloric acid, 82 pct ethanol and 3 pet glycerol and with a voltage of $11 \mathrm{~V}$ and a current of $60 \mathrm{~mA}$ at room temperature. Once the optical sensor in the polisher detected a hole in the center of the sample, the polishing was stopped. Subsequently, the sample was immersed in ethanol. The TEM analysis was carried out using a JEOL JEM-2200FS transmission electron microscope with field emission gun. The indexation of the TEM diffraction patterns was performed with CrysTbox software. ${ }^{[26]}$

$\mathrm{X}$-ray diffraction (XRD) analysis was performed on a double pulse weld and a double pulse-PB weld using a Bruker type D8-Advance diffractometer in Bragg-Brentano geometry with a graphite monochromator equipped with a Vantec position sensitive detector using $\mathrm{Co} \mathrm{K} \alpha$ radiation. Measurements were performed in the $2 \theta$ range of 40-100 deg with a step size of $0.035 \mathrm{deg}(2 \theta)$ and an acquisition time of $4 \mathrm{~s} / \mathrm{step}$.

Vickers microhardness measurements were conducted at $200 \mathrm{~g}$ load for 15 seconds loading time. Mechanical properties of the welds were evaluated by CTS tests and the tests were repeated three times for each weld. The weld nugget sizes of the CTS samples were measured with a Vernier caliper. Finally, the microstructures of the fractured CTS samples were investigated.

\section{RESULTS}

A schematic representation of a cross section for the AHSS subjected to a double pulse welding scheme is shown in Figure 1. During the first pulse, the primary weld nugget is produced. The second pulse results in a re-melted zone inside the primary weld nugget, forming a secondary weld nugget. The area within the primary weld nugget and outside the secondary weld nugget is annealed during the second pulse (referred as 'Annealed zone' in Figure 1). The locations of the samples taken for SEM and TEM studies within the weld nugget and the HAZ are schematically shown in Figure 1. The SEM micrographs of the welds studied taken from the weld nugget are shown in Figure 2. The weld nugget microstructures of the single pulse and double pulse welds both show a martensitic microstructure (Figures 2(a) and (b)). Carbides were found in the weld microstructures of the low-temperature post-weld heat-treated samples (single pulse-PB and double pulse-PB, Figures 2(c) through (f)); however, the SEM spatial resolution is not sufficient to confirm the type of carbides.

The X-ray diffractograms of the double pulse and double pulse-PB weld taken from the weld nugget zone are shown in Figures 3(a) and (b), with clear evidence of bcc martensite reflections for both samples. However, some traces of diffracting austenite planes (FCC) are detected in the diffraction pattern of the as-welded and heat-treated samples. The volume fraction of austenite is about 1 and $0.5 \mathrm{vol}$ pct in the double pulse and the double pulse-PB weld, respectively. First FCC peak has completely disappeared in the double pulse-PB diffraction pattern. Peaks would be expected at $2 \theta$ of $44,48.5$, and $50.6 \mathrm{deg}$ for $\varepsilon$ carbide and at $2 \theta$ of $44,50.2,51.2$, 52.2, 52.8, 53.8, and $57.7 \mathrm{deg}$ for cementite. Carbides were not detected from the XRD profiles. The strongest carbide peaks are hidden under the very strong ferrite peak and for very small particles (few hundred $\mathrm{nm}$ ), the diffraction peaks become boarder and disappear in the background, which makes it difficult to detect carbides with XRD.

Figure 4 shows a bright field TEM image taken from the weld nugget zone of the as-welded double pulse weld and the corresponding selected area diffraction (SAED) pattern. The lath martensite features are obvious in Figure 4(a) and the indexed SAED pattern (Figure 4(b)) shows the $F e(\alpha)$ reflections with zone axis of $\langle 0-10\rangle$. 

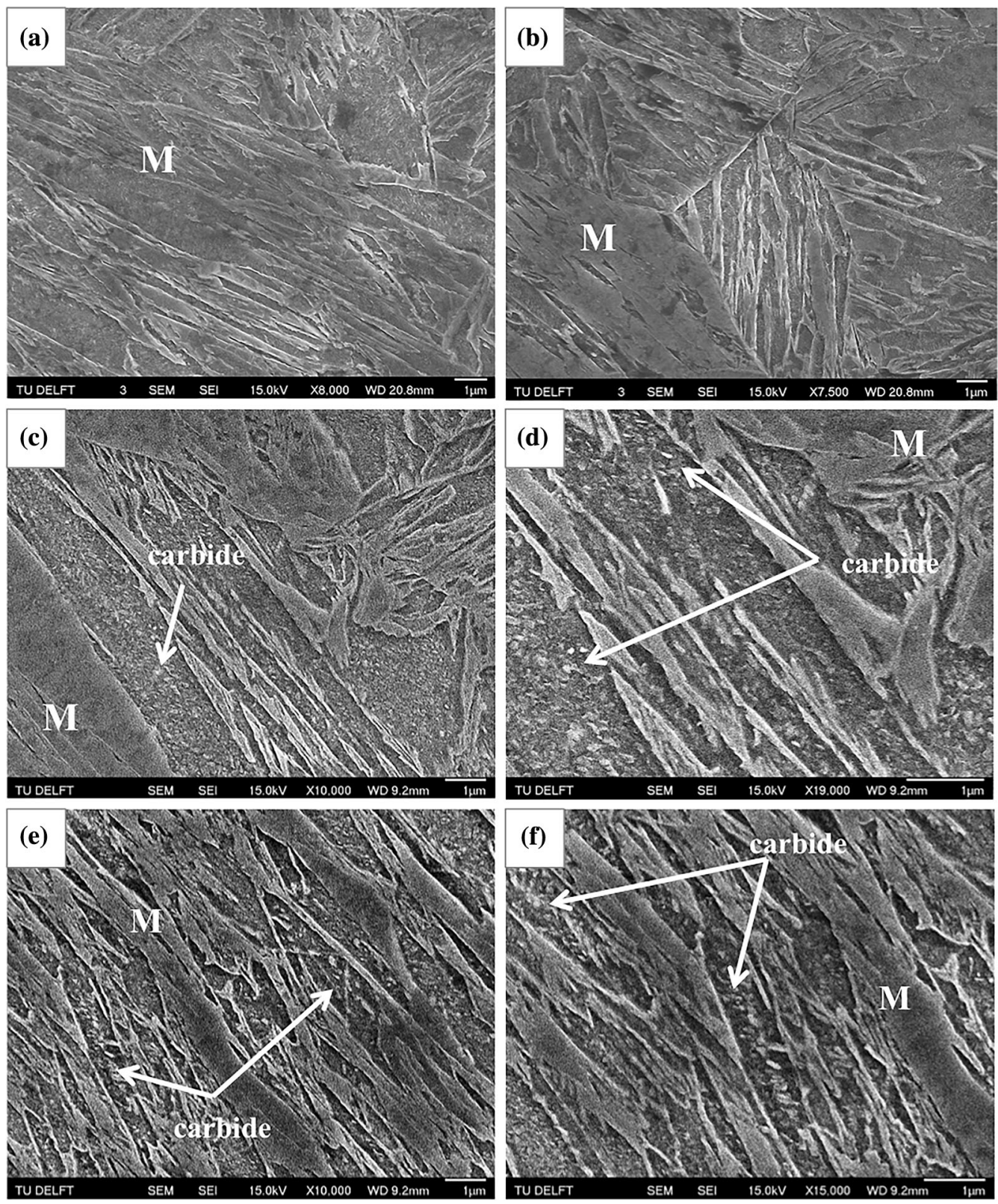

Fig. 2-SEM micrograph of the weld nugget of $(a)$ single pulse, $(b)$ double pulse, $(c)$ single pulse-PB, $(d)$ higher magnification of single pulse-PB, (e) double pulse-PB, and $(f)$ higher magnification of double pulse-PB.

No carbides were detected within the as-welded sample. The bright field TEM image taken from the HAZ of the double pulse weld and the corresponding SAED pattern are shown in Figure 5. The detected reflections are $\mathrm{Fe}$ $(\alpha)$ with zone axis of $\left\langle\begin{array}{llll}0 & 0 & 1\end{array}\right\rangle$. No carbide reflections were detected for these as-welded samples.

Figure 6 depicts the bright field image and the corresponding SAED pattern of the weld nugget of the double pulse-PB sample. In this case, carbides are detected in the SAED pattern. The carbide type was determined by SAED analysis to be $\varepsilon$-carbide with zone axis of $\left\langle\begin{array}{llll}0 & 1 & 1\end{array}\right\rangle$.

Figure 7(a) shows bright field TEM image taken from the HAZ of a heat-treated sample (double pulse-PB). The corresponding SAED pattern and the indexed pattern is shown in Figure 7(b). The e-carbide with zone axis of $\langle-1-21\rangle$ was detected after indexing the SAED pattern. Figure 7(c) shows the dark-field image of $\varepsilon$-carbide within the HAZ of double pulse-PB sample.

The CTS test data for single pulse, single pulse-PB, double pulse, and double pulse-PB welds are shown in Table III. The representative load-displacement curves of the welds are shown in Figure 8(a). In our previous work, ${ }^{[5,6,8]}$ it has been shown that the double pulse weld shows higher CTS and displacement in comparison with the single pulse weld, although the weld nugget size of both welds is the same. Figure 8(a) and Table III show that the PB heat-treated samples (single pulse-PB and double pulse-PB) show significantly higher CTS and displacement than the as-welded samples (single pulse 
and double pulse weld, respectively). The highest CTS performance is achieved by the double pulse-PB sample with average CTS level of $8.4 \pm 1.2 \mathrm{kN}$ and average displacement at max. force of $12.1 \pm 1.0 \mathrm{~mm}$ (number

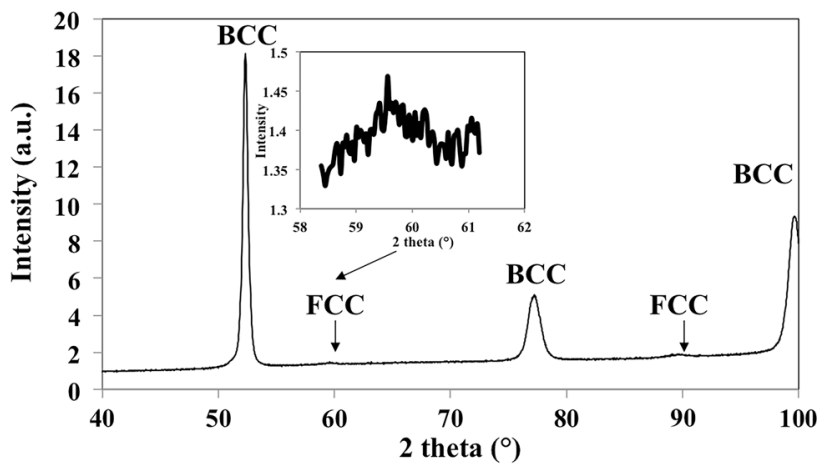

(a)

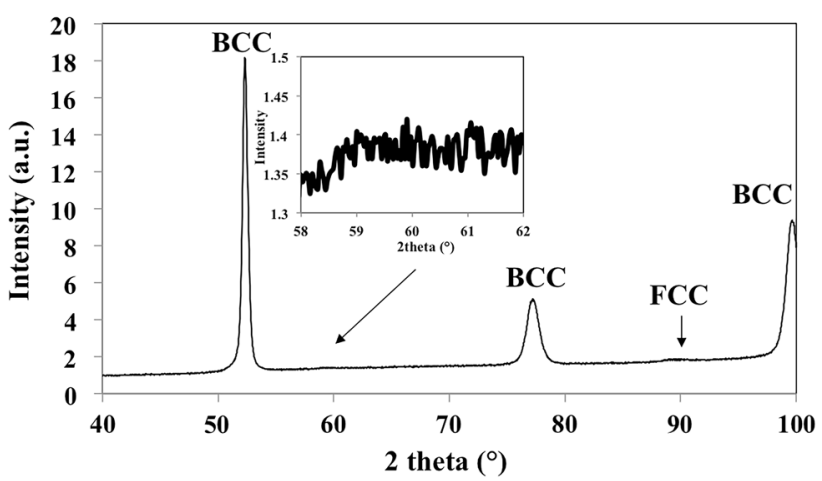

(b)

Fig. 3-X-ray diffraction profile of the $(a)$ as-welded (double pulse weld) and (b) heat-treated (double pulse-PB) sample taken from the weld nugget zone. of samples per set $=3$ ). The energy absorption capability (absorbed energy to maximum load) for the welds is depicted in Figure 8(b). The highest energy absorption capability is obtained for the double pulse-PB sample. Representative failure areas of different welds are shown in Figure 9. Single pulse and single pulse-PB welds show partial interfacial failure (PIF; Figures 9(a) and (b)). The PIF mode is the failure mode in which the fracture first propagates in the fusion zone and then is redirected in the thickness direction. At the same time, double pulse and double pulse-PB show the favorable full plug failure (PF) mode (Figures 9(c) and (d)). The full PF mode is the failure mode in which the failure occurs via withdrawal of the entire weld nugget from one of the sheets. The PF mode exhibits the most satisfactory mechanical properties.

Note specifically that the PB thermal cycle after welding in the present work does not change the failure mode of the CTS samples. The microhardness profile of the welds studied is shown in Figure 10. The average weld nugget microhardness of single pulse and double pulse weld is 512 and $520 \mathrm{HV}_{200 \mathrm{~g}}$, respectively. The weld nugget microhardness of single pulse-PB and double pulse-PB weld is 505 and $510 \mathrm{HV}_{200 \mathrm{~g}}$, respectively. Although, a reduction of about $10 \mathrm{HV}_{200 \mathrm{~g}}$ is shown in hardness values after heat treatment, this small drop by itself does not explain the large difference in CTS behavior.

The results of mechanical tests confirm that the PB thermal cycle can significantly enhance the mechanical performance of the AHSS.

The fractured surfaces of the welds are depicted in Figure 11. The single pulse weld and single pulse-PB weld with partial PF mode under peel loading show a mixed brittle and ductile fracture (Figures 11(a) and (c)). However, the double pulse weld and double pulse-PB weld with full PF in CTS test show dimples that are representative for a ductile failure (Figures 11(b) and (d)).
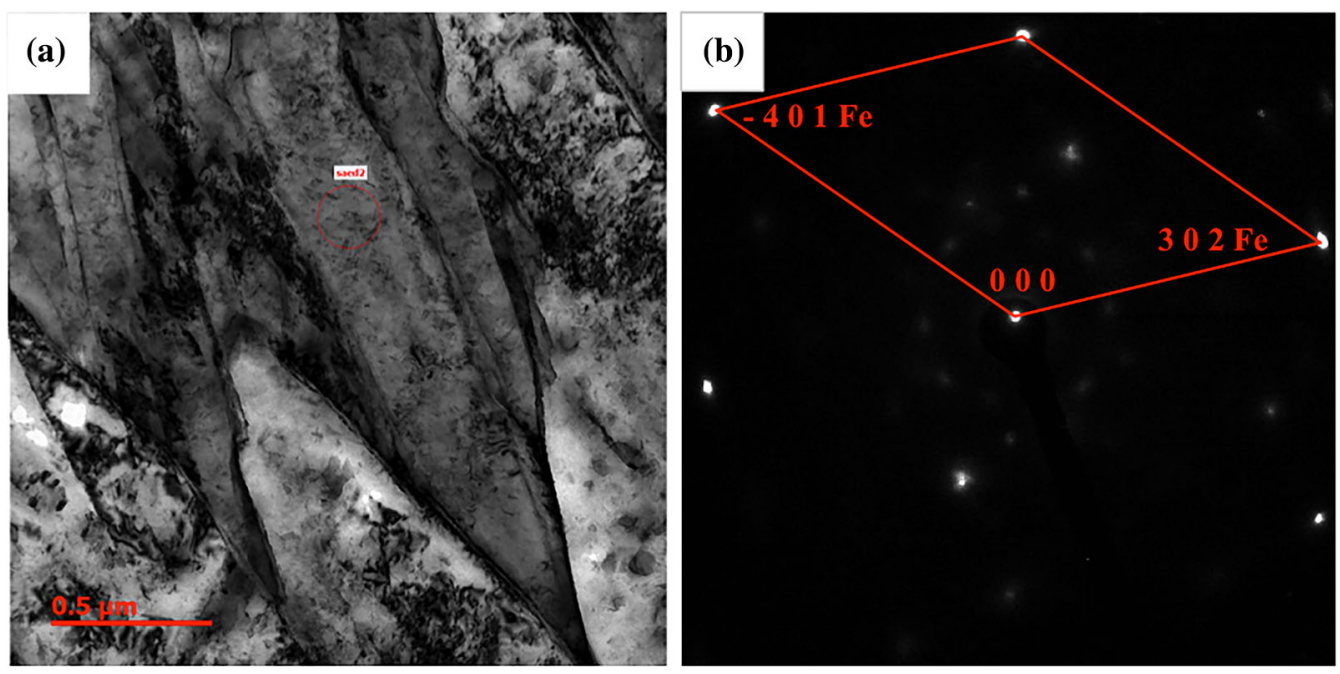

Fig. 4 - (a) Bright field micrograph taken from the weld nugget of the double pulse weld, $(b)$ corresponding SAED pattern Fe $(\alpha)$ zone axis $\langle 0-10\rangle$. 

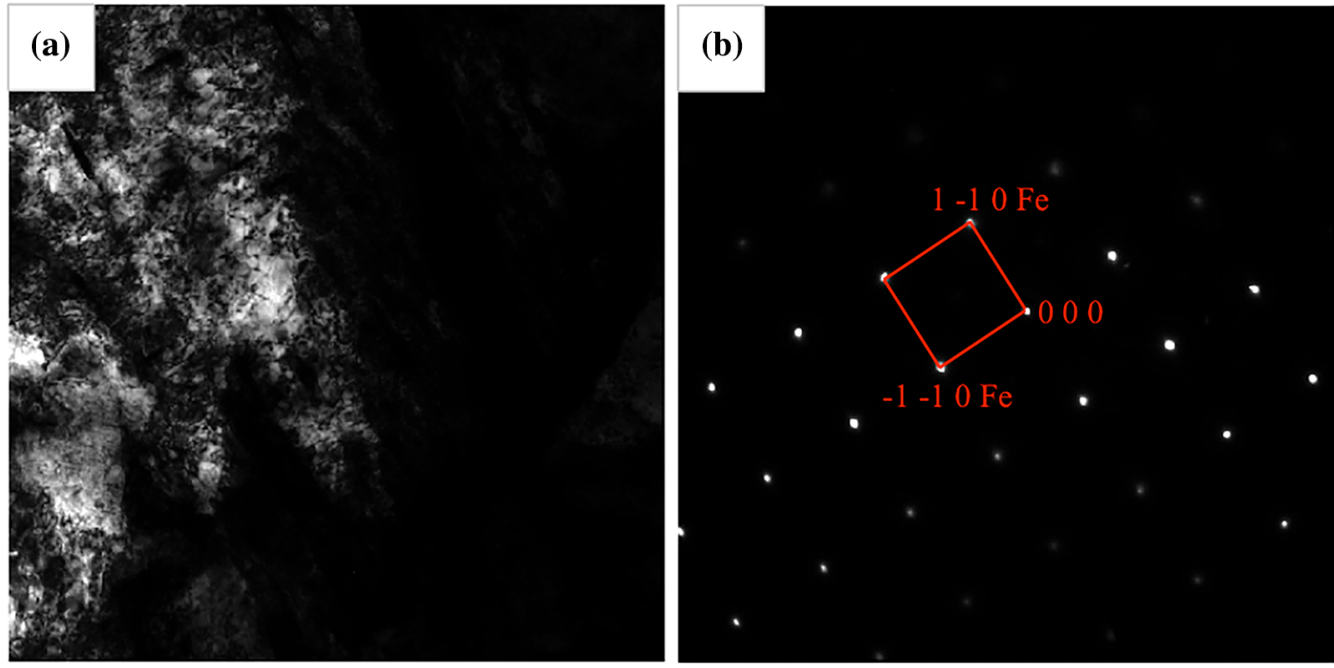

Fig. 5- (a) Bright field micrograph taken from the HAZ of the double pulse weld, $(b)$ corresponding SAED pattern Fe $(\alpha)$ zone axis $\langle 001\rangle$.
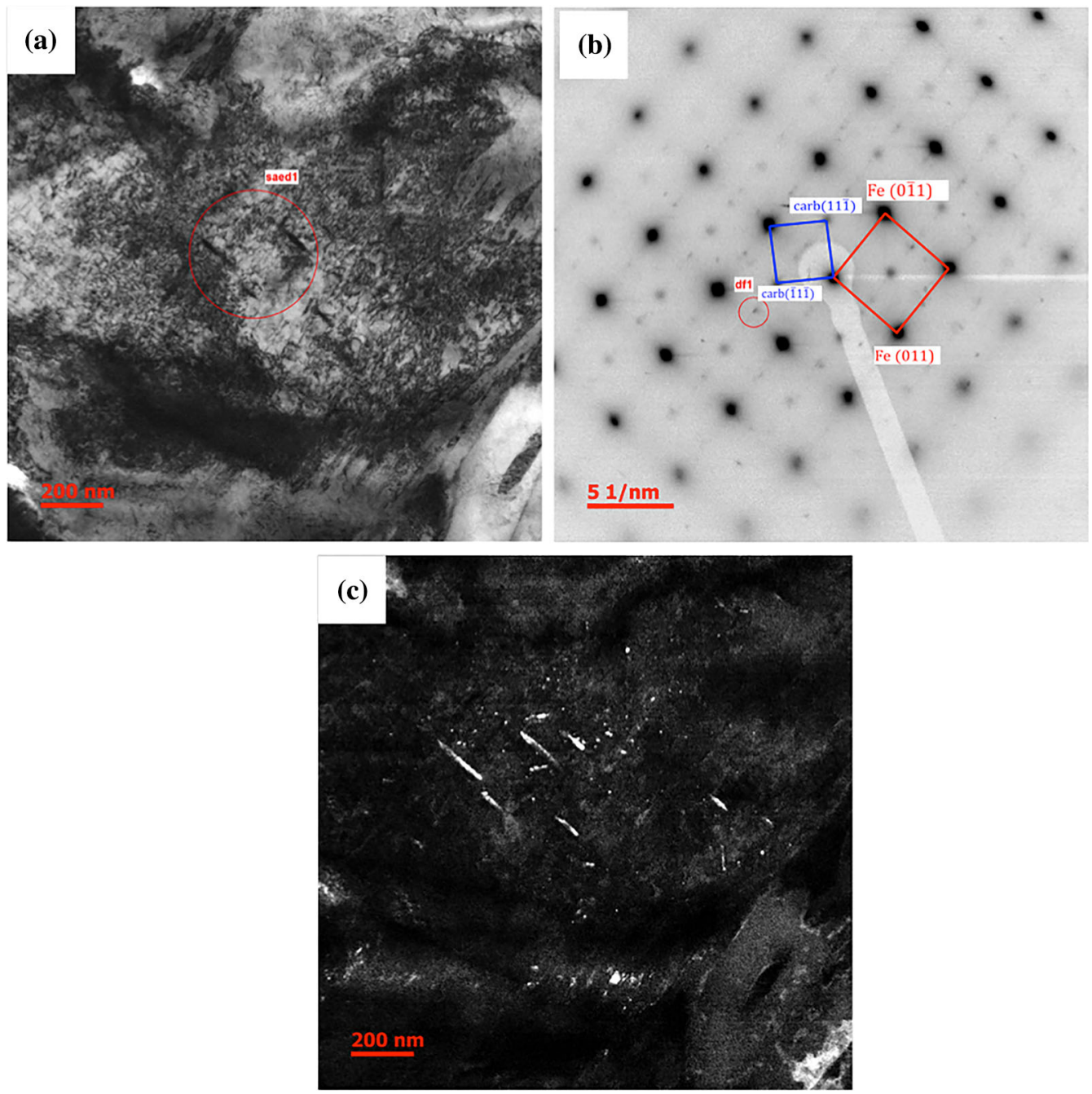

Fig. 6- (a) Bright field micrograph taken from the weld nugget of the double pulse-PB weld, $(b)$ corresponding indexed SAED pattern determined with CrysTbox software to be $\varepsilon$-carbide with zone axis $\left\langle\begin{array}{lll}0 & 1 & 1\end{array}\right\rangle$ with excellent estimation rate, and $(c)$ dark field image of $\varepsilon$-carbide. 

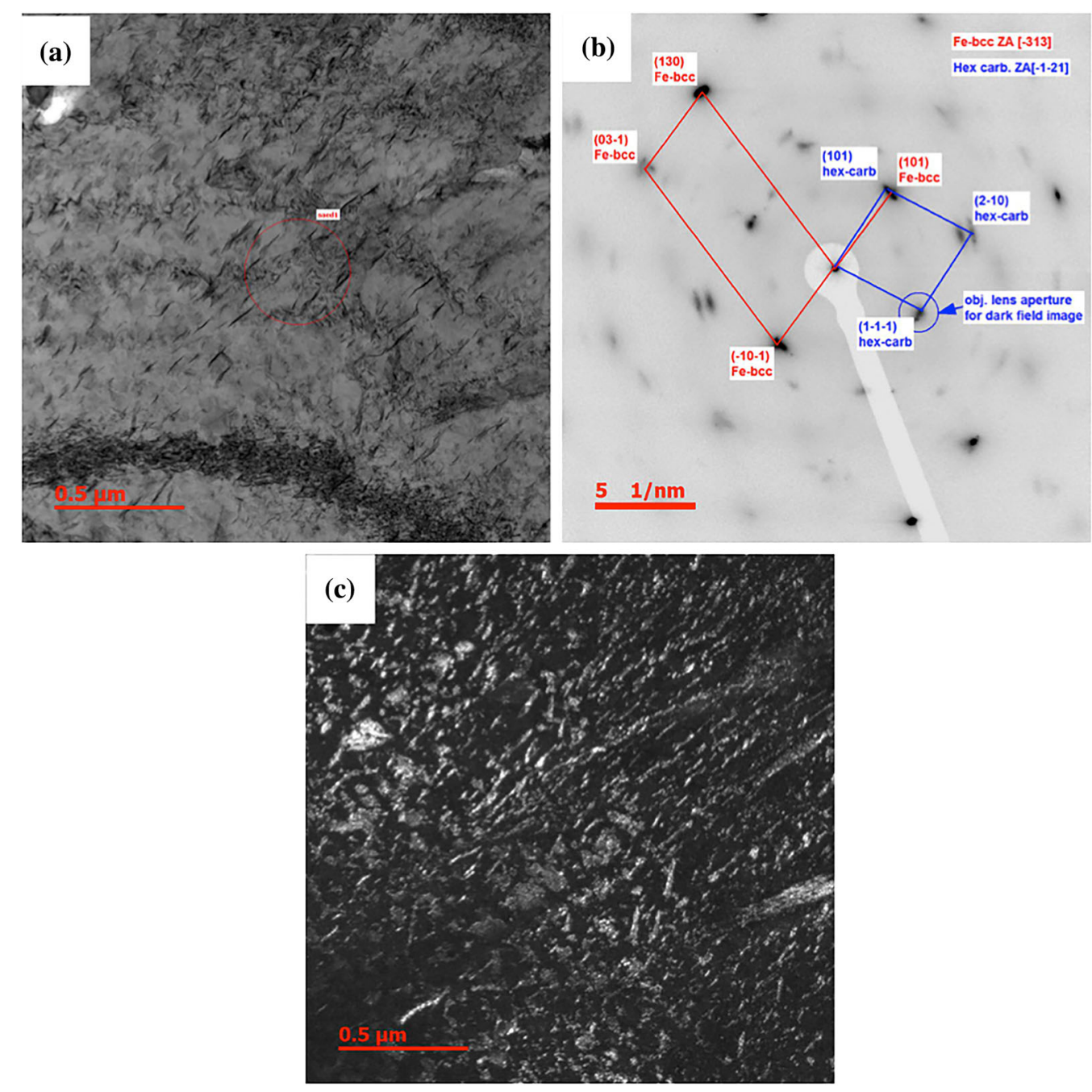

Fig. 7- (a) Bright field micrograph taken from the HAZ of the double pulse-PB sample, $(b)$ corresponding indexed SAED pattern determined with CrysTbox software to be $\varepsilon$-carbide with zone axis $\langle-1-21\rangle$ with excellent estimation rate, and $(c)$ dark-field image of $\varepsilon$-carbide.

Table III. Cross Tension Strength (CTS) Test Data

\begin{tabular}{lccc}
\hline Weld & $\begin{array}{c}\text { Average Maximum Force }(\mathrm{kN}) \text { CTS } \\
(n=3)\end{array}$ & $\begin{array}{c}\text { Average Displacement at Maximum Force } \\
(\mathrm{mm})(n=3)\end{array}$ & Failure Mode \\
\hline $\begin{array}{l}\text { Single Pulse } \\
\text { Single }\end{array}$ & $3.8 \pm 0.3$ & $6.0 \pm 0.5$ & $\begin{array}{c}\text { partial interfacial failure } \\
\text { partial interfacial failure }\end{array}$ \\
$\quad$ Pulse-PB & $5.2 \pm 0.3$ & $6.1 \pm 0.5$ & plug failure \\
Double Pulse & & & plug failure \\
$\begin{array}{l}\text { Double } \\
\text { Pulse-PB }\end{array}$ & $5.7 \pm 0.1$ & $12.0 \pm 0.2$ & \\
\hline
\end{tabular}

\section{DISCUSSION}

In previously reported work, ${ }^{[7,8]}$ it was shown that the mechanical properties of resistance spot welded AHSS can be significantly improved by applying double pulse welding scheme. Improvement in mechanical performance of double pulse welds has been reported to be related to the redistribution of alloying elements such as phosphorous and modification of the lath martensite substructure at the weld nugget edge during second pulsing. ${ }^{[7,8]}$ The mechanical performance of the welds has been improved even further after the application of a PB thermal cycle. In the current work, we describe the effect of the PB thermal cycle on the microstructural features of the single and double pulse welds.

The increase in CTS of heat-treated single pulse and double pulse welds is 37 and 47 pct, respectively. Energy absorption as a representative of the weld crashworthiness has also increased after the application of the heat treatment. The double pulse-PB weld has the highest absorbed energy level to maximum load (about $48.5 \mathrm{~J}$ ), 


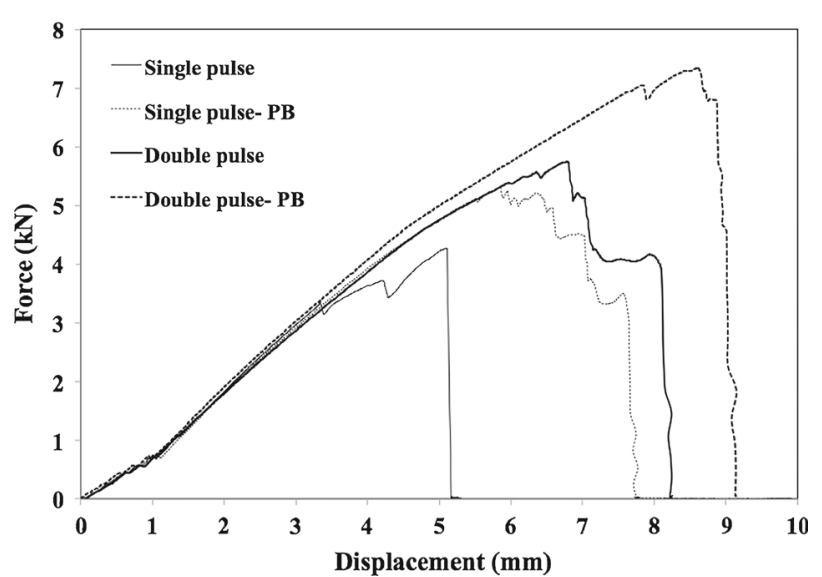

(a)

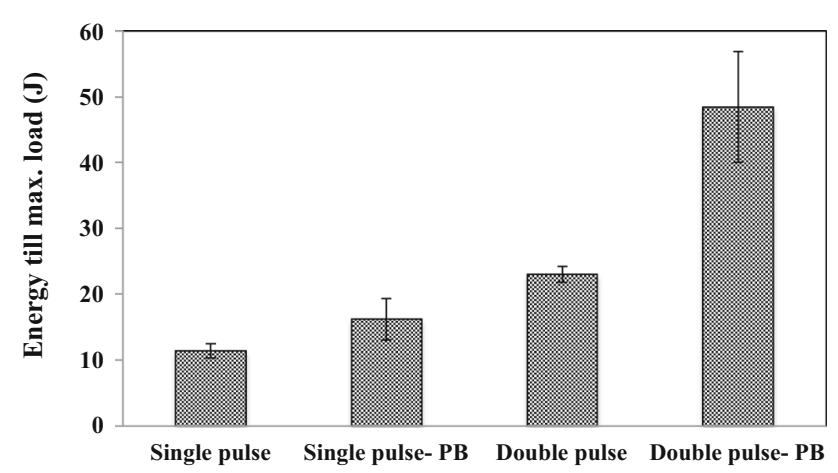

(b)

Fig. 8 - (a) Schematic representation of force-displacement curves, (b) energy absorption till maximum load in single pulse, double pulse, single pulse-PB, and double pulse-PB welds in cross tension strength tests $(n=3)$.

which is in the order of a standard (first generation) AHSS. Although a constant hardness reduction of about $7 \mathrm{HV}_{200 \mathrm{~g}}$ is shown in heat-treated welds, this hardness drop is believed to be too small to explain the large increase in CTS. Smith et al. ${ }^{[21]}$ have reported similar effects of a baking cycle on the hardness levels of AHSSs welds.

Possible factors contributing to the increased weld CTS and energy absorption increment after a PB thermal cycle could be tempering of martensite, i.e., carbide formation and thereby increasing the martensite fracture toughness, changes in retained austenite and hydrogen content of the weld and/or changes in residual stresses within the weld nugget and the HAZ.

The changes in residual stresses and fracture toughness of martensite after a typical PB cycle are measured using synchrotron XRD and digital image correlation techniques, respectively. First indications are that the stress levels are affected by a PB cycle and are typically reduced and the fracture toughness of martensite is improved after a PB cycle.

The microstructural analysis of the as-welded samples either in the weld nugget or the HAZ shows a lath martensite microstructure (Figures 4 and 5). The high cooling rates of RSW and the relatively high amount of alloying elements in AHSSs compared with conventional steels result in an almost fully martensitic weld nugget and a coarse and fine grained HAZ in these welds.

The baking thermal cycle (at $453 \mathrm{~K}\left(180{ }^{\circ} \mathrm{C}\right)$ for 20 minutes) is similar to low-temperature tempering of the steels. As shown in Figure 3, the retained austenite is calculated to be about 1 vol pct in the as-welded sample and about $0.5 \mathrm{vol}$ pct in the heat-treated sample. The transformation of RA to bainite could occur during heat treatment. However, the decomposition of retained austenite is reported only for heat treatments higher than $473 \mathrm{~K}\left(200{ }^{\circ} \mathrm{C}\right) .{ }^{[20]}$ The small change in RA could be neglected in the present work. The effects of tempering on the martensite microstructure depending on the tempering temperature have been reported. During tempering at temperatures below $373 \mathrm{~K}$ $\left(100{ }^{\circ} \mathrm{C}\right)$, the carbon atoms segregate to the interstitial sites and dislocations and form carbon clusters. ${ }^{[20,27]} \mathrm{At}$ temperatures between $353 \mathrm{~K}$ and $473 \mathrm{~K}\left(80{ }^{\circ} \mathrm{C}\right.$ and $200{ }^{\circ} \mathrm{C}$ ), precipitation of carbides could occur. ${ }^{[20]}$ At higher tempering temperatures, recovery, recrystallization and decomposition of retained austenite occur. ${ }^{[20]}$ TEM analysis of the heat-treated welds at the weld nugget and the HAZ reveals $\varepsilon$-carbide precipitation (Figures 6 and 7).

The chemical composition of steel together with the thermal cycle determines the microstructure and mechanical properties after tempering. Grange et al. ${ }^{[28]}$ has reported that the hardness reduction of martensite in an iron- $0.2 \mathrm{wt}$ pet carbon alloy after $473 \mathrm{~K}\left(200{ }^{\circ} \mathrm{C}\right)$ tempering for 1 hour is about $50 \mathrm{HV}$. However, adding $1 \mathrm{wt}$ pct Si to the system could increase the hardness of the tempered martensite by about $40 \mathrm{HV} \cdot{ }^{[28,29]}$ Also, $\mathrm{Si}$ inhibits the conversion of $\varepsilon$-carbide to cementite and increases the stability range of $\varepsilon$-carbide. Alloying elements such as $\mathrm{Mn}, \mathrm{P}$, and Mo seem to have no effect on the hardness of martensite after tempering. ${ }^{[28]}$ The steel studied consists of higher $\mathrm{C}$ and $\mathrm{Si}$ levels than conventional AHSS. These increased levels of $\mathrm{C}$ and $\mathrm{Si}$ are typical alloying strategies to obtain the desired strength-ductility properties. In this steel, the PB thermal cycle (at $453 \mathrm{~K}\left(180^{\circ} \mathrm{C}\right)$ for 20 minutes) did not lead to severe hardness reduction due to its chemical composition (Table I). As reported in the literature and also confirmed in our work, the hardness reduction is about $7 \mathrm{HV}$.

It is well reported that the weld nugget and HAZ hardness reduction leads to an increase in CTS and displacement of the spot welds. ${ }^{[5]}$ Lalam $^{[30]}$ has reported that paint baking improves the CTS about $1.78 \mathrm{kN}$ with reducing the CGHAZ hardness about 60 Vickers for a weld that has been welded with the current of $9.7 \mathrm{kA}$. However, in our results, the hardness reduction is low and it is very unlikely that the small decrease in microhardness level leads to the significant increase in CTS. However, this decrease can be a reason for a displacement increment in CTS testing. In the single pulse welds, the effect of segregation during 

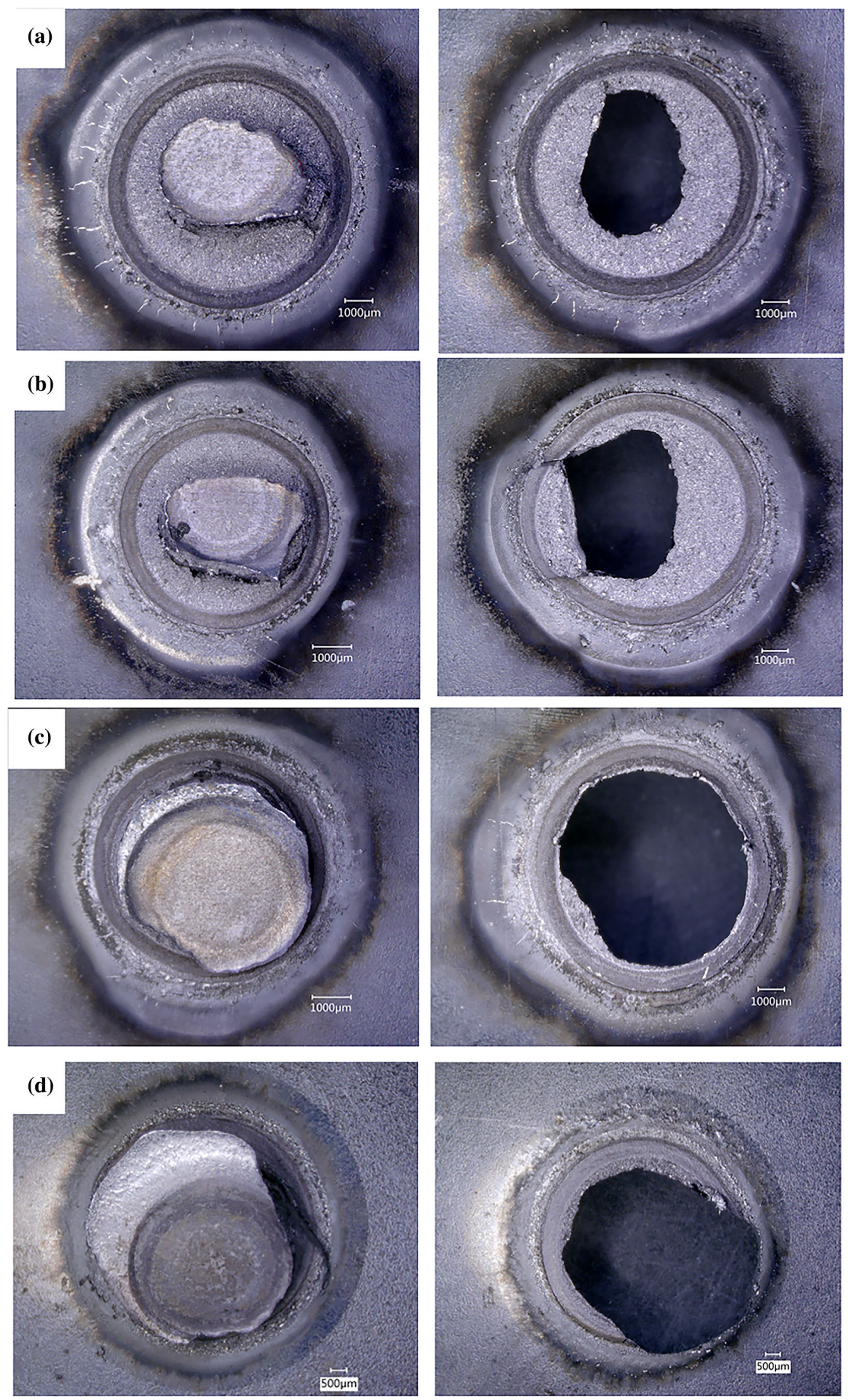

Fig. 9-Representative failure modes of $(a)$ single pulse weld, $(b)$ single pulse-PB, $(c)$ double pulse weld, and $(d)$ double pulse-PB for cross tension strength tests. 


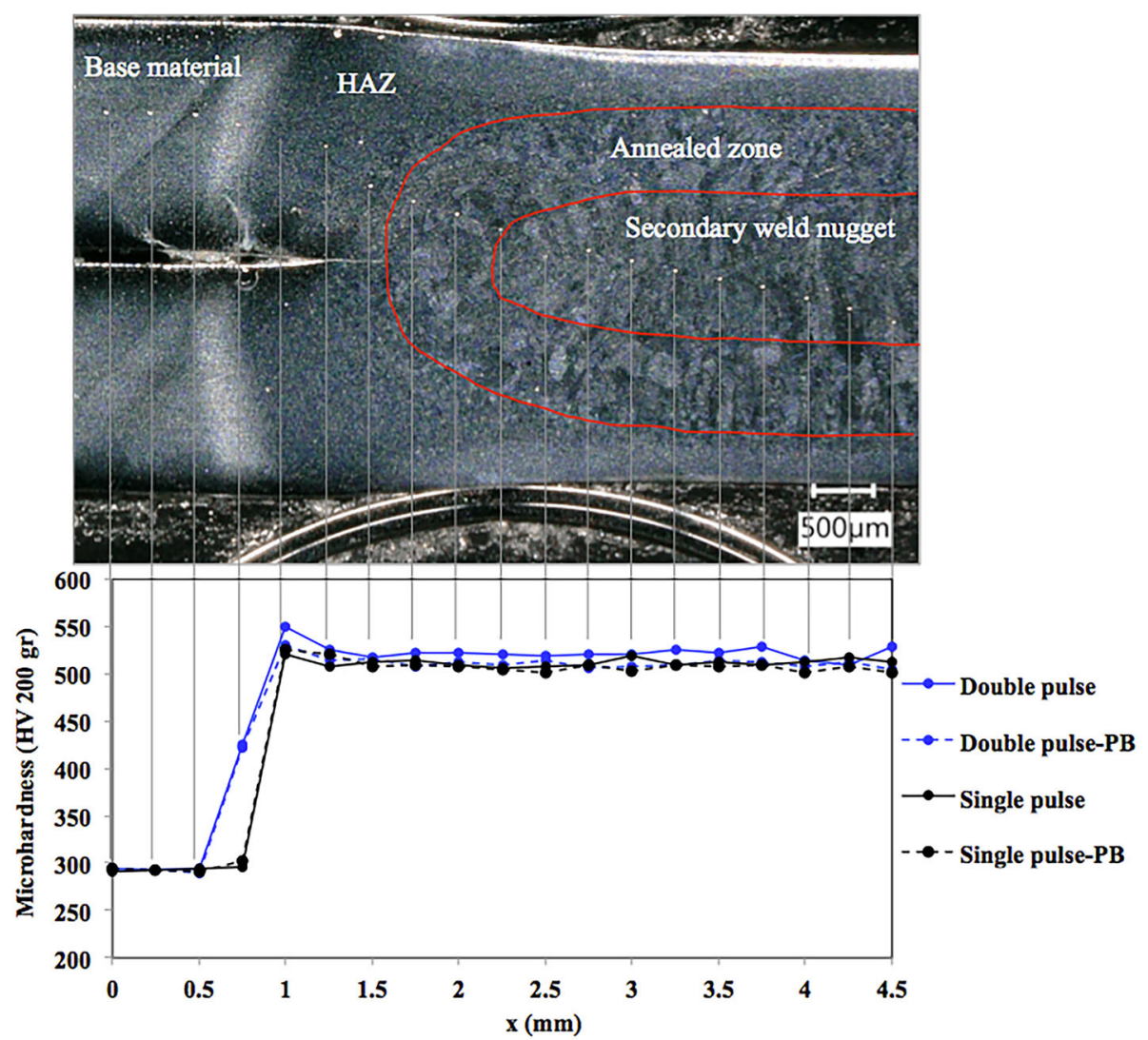

Fig. 10-Microhardness profile of the welds studied. The indents are shown on a cross section of a double pulse weld.

solidification on the mechanical behavior is most dominant. This leads to PIF, i.e., failure of the weld metal. The PB cycle results in the formation of $\varepsilon$-carbides in the HAZ and weld nugget and possibly a decrease of dislocation density. This increases the strength and displacement of the weld in CTS testing, but is not changing the mode of failure. If a double pulse welding sequence is applied, the segregation is decreased and grain morphology and martensite substructure are modified and a favorable failure mode has been adopted. The joint fails in the HAZ. Again the PB cycle promotes precipitation taking place in the weld nugget and HAZ microstructure. This results in a general improvement of mechanical properties. The main factor, which decides whether a favorable fracture mode is obtained, is thus related to elemental segregation. The PB cycle has a general strengthening effect. It also has been reported that the presence of about 1 vol pct $\varepsilon$-carbide has a contribution of about $130 \mathrm{MPa}$ for the yield strength of a quenching and partitioning steel. ${ }^{[31]}$

Crack initiation during loading is indicated by the pop-ins in the load-displacement curves of CTS test (Figure 8(a)). The crack initiation is delayed in heat-treated samples. Delayed crack initiation in heat-treated welds is probably due to increase in fracture toughness of the martensite. This is partly supported by the fact that the failure modes of the welds do not change, while the CTS does increase. The fracture toughness of martensite and tempered martensite in steel studied will be quantitatively reported in our future work.

\section{CONCLUSIONS}

The following conclusion can be drawn based on this study:

(1) Baking cycle has significantly increased the CTS and energy absorption capability of both single and double pulse resistance spot welded AHSS.

(2) Baking cycle has no noticeable effect on the failure modes of the CTS samples.

(3) Only a minor reduction in weld/HAZ hardness was found for the paint baked samples; this hardness reduction by itself could not explain the increase in CTS.

(4) TEM analysis shows that the baking cycle resulted in precipitation of $\varepsilon$-carbides within the weld nugget and the HAZ of the welds.

(5) Precipitation of $\varepsilon$-carbides and increase in fracture toughness of the martensite after baking cycle could be the dominant factors in improved CTS properties of the welds.

(6) Double pulse welding, followed by a baking cycle, provides AHSS resistance spot welds with good mechanical performance. 

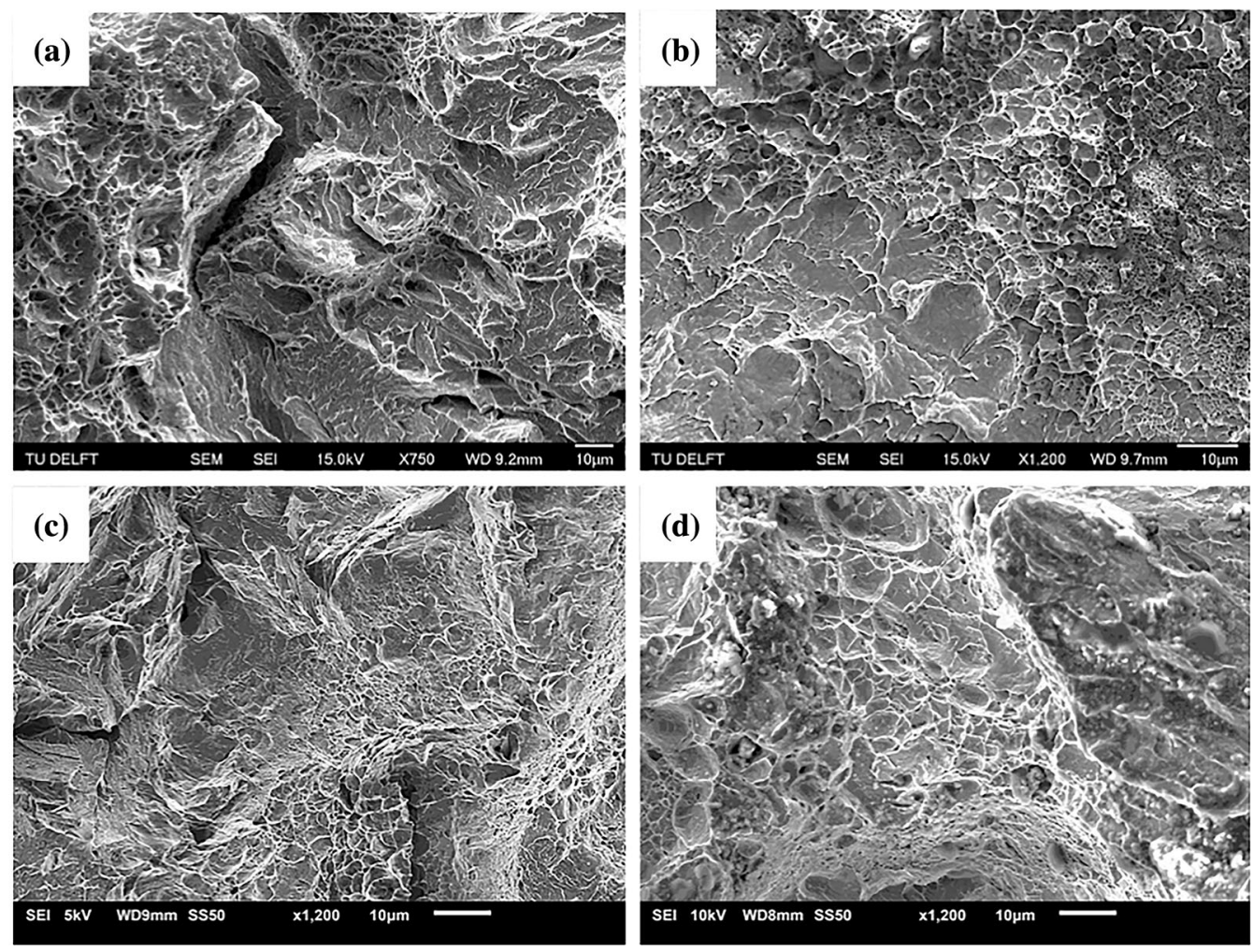

Fig. 11-Fractured surfaces of the CTS samples $(a)$ single pulse weld indicating mixed brittle-ductile fracture, $(b)$ double pulse weld indicating ductile fracture, $(c)$ single pulse-PB indicating mixed brittle-ductile fracture, and $(d)$ double pulse-PB indicating ductile fracture.

\section{ACKNOWLEDGMENTS}

The authors would like to acknowledge Dr. Vitaliy Bliznuk for his help and advice on TEM work. This research was carried out under Project Number F22.7.13507 in the Framework of the Partnership Program of the Materials Innovation Institute M2i (www.m2i.nl) and the Foundation of Fundamental Research on Matter (FOM) (www.f om.nl), which is part of the Netherlands Organization for Scientific Research (www.nwo.nl).

\section{OPEN ACCESS}

This article is distributed under the terms of the Creative Commons Attribution 4.0 International License (http://creativecommons.org/licenses/by/4.0/), which permits unrestricted use, distribution, and reproduction in any medium, provided you give appropriate credit to the original author(s) and the source, provide a link to the Creative Commons license, and indicate if changes were made.

\section{REFERENCES}

1. H.R. Rezaei Ashtiani and R. Zarandooz: Metall. Mater. Trans. A, 2015, vol. 46A, pp. 4095-4105.

2. W. Tong, H. Tao, X. Jiang, N. Zhang, M.P. Marya, L.G. Hector, and X.Q. Gayden: Metall. Mater. Trans. A, 2005, vol. 36A, pp. 2651-69.
3. N.D. Raath, D. Norman, I. Mcgregor, S. Hepple, R. Dashwood, and D.J. Hughes: Metall. Mater. Trans. A, 2018, https://doi.org/ 10.1007/s11661-018-4502-x.

4. M.D. Tumuluru: Weld. J., 2006, vol. 85, pp. 31-37.

5. M. Pouranvari and S.P.H. Marashi: Sci. Technol. Weld. Join., 2013, vol. 18, pp. 361-403.

6. C. Sawanishi, T. Ogura, and K. Taniguchi: Sci. Technol. Weld. Join., 2014, vol. 19, pp. 52-59.

7. P. Eftekharimilani, E.M. van der Aa, M.J.M. Hermans, and I.M. Richardson: Sci. Technol. Weld. Join., 2017, vol. 22, pp. 545-54.

8. P. Eftekharimilani, E.M. van der Aa, M.J.M. Hermans, and I.M. Richardson: Weld. World, 2017, vol. 61, pp. 691-701.

9. T.B. Hilditch, J.G. Speer, and D.K. Matlock: Mater. Des., 2007, vol. 28 , pp. 2566-76.

10. E.M. Van der Aa, M. Amirthalingam, J. Winter, D.N. Hanlon, M.J.M. Hermans, M. Rijnders, and I.M. Richardson: Mathematical Modelling of Welding Phonomena 11, Verlag der Technischen Universität Graz, Graz, 2015, pp. 175-93.

11. A. Grajcar, M. Morawiec, M. Rozanski, and S. Stano: Opt. Laser Technol., 2017, vol. 92, pp. 52-61.

12. S. Stano, A. Grajcar, Z. Wilk, M. Rozanski, P. Matter, and M. Morawiec: Arch. Metall. Mater., 2016, vol. 61, pp. 731-40.

13. A. Trautmann: Ph.D. Thesis, München, Techn. Univ., 2008.

14. M. Morawiec, M. Rozanski, A. Grajcar, and S. Stano: Arch. Civ. Mech. Eng., 2017, vol. 17, pp. 145-53.

15. S. Iqbal, M.M.S. Gualini, and A. Rehman: Opt. Laser Technol., 2010, vol. 42, pp. 93-98.

16. X. Xue, A.B. Pereira, J. Amorim, and J. Liao: Metals, 2017, vol. 7, pp. $1-18$.

17. F. Nikoosohbat, Sh. Kheirandish, M. Goodarzi, and M. Pouranvari: Mater. Technol., 2015, vol. 49, pp. 133-38.

18. ASM Handbook. Heat Treating, vol. 4. ASM International. ISBN-13: 978-0-87170-379-8.

19. I.B. Timoknina, P.D. Hodgson, S.P. Ringer, R.K. Zheng, and E.V. Pereloma: in New Developments on Metallurgy and Applications of High Strength Steels Conference, Buenos Aires, Argentina, 26-28 May 2008. 
20. G.R. Speich and W.C. Leslie: Metall. Trans. A., 1972, vol. 3, pp. 1043-54.

21. S. Smith, T. Okada, N.J. den Uijl, T. van der Veldt, M. Uchihara, and K. Fukui: in International Automotive Body Congress (IABC), Vaals, The Netherlands, June 2009.

22. T. Okada, S. Smith, N.J. den Uijl, T. van der Veldt, M. Uchihara, and K. Fukui: in Proceedings of the 8th International Welding Symposium, Japan Welding Society. November 2008.

23. M. Tumuluru: Weld. J., 2010, vol. 89, pp. 91s-100s.

24. VDA 239-100 Material Specification: Sheet Steel for Cold Forming, 5 May 2016.

25. SEP 1220-2: Testing and Documentation Guideline for the Joinability of Thin Sheet of Steel-Part 2: Resistance Spot Welding. VDEh Standard; 2007 (Technical Report 08).
26. CrysTbox diffract GUI2.19 by Miloslav Klinger.

27. G. Kraus: The Metallurgical Society of AIME, Ferrous Metallurgy Committee, Warrendale, PA, 1983, pp. 101-23.

28. R.A. Grange, C.R. Hribal, and L.F. Porter: Metall. Trans. A, 1977, vol. 8A, pp. 1775-85.

29. G. Krauss: Metall. Mater. Trans. A, 2001, vol. 32A, pp. 861-77.

30. S.H. Lalam: Proc. Great Des. Steels Semin., Livonia, MI, USA, March 2005, AISI. http://www.autosteel.org/Great\%20Designs\% 20in \%20Steel.aspx.

31. F. HajyAkbary, J. Sietsma, G. Miyamoto, N. Kamikawa, R.H. Petrov, T. Furuhara, and M.J. Santofimia: Mater. Sci. Eng., A, 2016, vol. 677, pp. 505-14. 